\title{
The Turkish adaptation of leisure facilitator scale: a validity and reliability study
}

\author{
Gürbüz B. ${ }^{1 \mathrm{ACDE}}$, Öncü E. ${ }^{2 \mathrm{ACE}}$, Emir E. ${ }^{3 \mathrm{BD}}$ \\ ${ }^{1}$ Faculty of Sport Sciences, Department of Sports Management, Ankara University, Ankara, Turkey \\ ${ }^{2}$ Faculty of Sport Sciences, Department of Physical Education and Sport Teaching, Trabzon University, Trabzon, \\ Turkey \\ ${ }^{3}$ Yaşar Doğu Faculty of Sport Sciences, Department of Physical Education and Sport Teaching, Ondokuz Mayls \\ University, Samsun, Turkey
}

Authors' Contribution: A - Study design; B - Data collection; C - Statistical analysis; D - Manuscript Preparation; E - Funds Collection.

\begin{abstract}
Purpose: $\quad$ The aim of this study to test the reliability and validity of “Leisure Facilitator Scale" (LFS) for Turkish university students.

Material: $\quad$ The sample included 111 female and 132 male, and totally 243 faculty of sport sciences' students for this study. The LFS which was consists of 3 subscales and 27 items was used to collect data. Besides descriptive statistics, confirmatory factor analysis was applied to test the factor structure of LFS. Pearson's productmoment coefficients were used to examine correlations between the factors. For determining the reliability of the scale Cronbach Alpha coefficient was calculated.

Results: $\quad$ Analysis indicated that the Turkish version of the LFS constituted of 3 subscales and 16 items. Totally 11 items were excluded from the Turkish version because of lower factor loadings. Factor loading values of the items ranged between 0.49 and 0.76 . Cronbach Alpha values were calculated as $0.79,0.66,0.78$ and 0.86 for the subscales and total scale respectively.

Conclusions: In conclusion, results indicated that "Leisure Facilitator Scale" Turkish adapted form can be used as a valid and reliable measurement tool to examine the factors that facilitate leisurely participation of students.

Keywords: leisure, facilitators, adaptation, university students.
\end{abstract}

\section{Introduction}

Many researchers studying leisure argue that each individual should physically and mentally experience leisure free from the stress of everyday life and each individual has the right to freely choose a leisure activity $[1,2,3]$. Kraus [4], likewise, defines leisure as the time period in which individuals satisfy their feelings of emotion, pleasure and entertainment by freely choosing their activities, and thereof fulfill their self-realization by unveiling their potential. Several others also conducted studies suggesting that participation into leisure activities provides the individual multiple benefits such as physical and mental well-being, happiness, socialization and relaxation $[5,6]$. Not every individual, however, share the same benefits from the leisure tactivities equally. Crawford and Godbey [7] define this situation with the categorical constraints by labelling them "personal, interpersonal and structural" constraints in leisure participation.

The factors that constraint or limit participation into leisure activities have significant role in understanding an individual's activity behavior and in establishing a causality link between the individual and the activity. In this respect, it is first essential to comprehend the leisure constraints approach in order to understand the causes of participation/non-participation in leisure activities and the relations between these causes and aforementioned factors $[8,9]$. According to this approach, the non-participation factors involve the personal factors such as the needs, past experiences, beliefs and attitudes; interpersonal factors (c) Gürbüz B., Öncü E., Emir E., 2019

doi:10.15561/20755279.2019.0202 such as the family, social environment and friends; and structural factors such as the finances, facilities, socioeconomic status, ethnic composition and gender roles $[7,10,11]$. For other researchers $[12,13]$, however, the leisure constraints approach can sometimes be a limited approach in understanding leisure behavior. People usually participate into these activities not because they are stripped off all the constraints and become free but the leisure time space is a free zone. On this issue, Kim et al. [14] suggested that the factors that facilitate participation into leisure activities should be investigated as well as the constraints in order to explain the nature of participation into leisure activities and to ensure a wider participation. Likewise, the strategy model developed by Hubbard and Mannel [15] posited that having some constraints for activity participation does not necessarily mean that the individual will not participate in leisure activities. Individuals can develop some strategies for coping with the constraints and participation can be realized. Actually, the underlying phenomena behind the strategic choices are the facilitating factors for leisure activity participation [16]. It is observed by some researchers that determining the facilitating factors of leisure participation has significant role in explaining the participation/nonparticipation behavior since the strategy models that aim to explain the participation behavior of the individuals in leisure activities in terms of leisure constraints and the ways to cope with these constraints are interrelated with the facilitating factors in essence $[14,17]$. In regard to this point, investigating the facilitating factors for leisure 
participation carry important weight.

The survey of the literature on the leisure facilitators reveal the fact that most of the studies date fifteen years back $[13,18,19]$ while the number of studies on the same topic in Turkey is very limited [20, 21, 22]. In the Turkish case, it is probably due to the lack of an adapted scale to measure the facilitating factors for leisure activity participation. Therefore, the purpose of this study is to adapt the Leisure Facilitator Scale developed by Kim et al., [14] into Turkish and examine the psychometric properties of the scale. The results of this study can help opening a new dimension for future studies that target increasing the participation of individuals into the leisure tactivities.

\section{Leisure Facilitators}

Opposite of the concept of "leisure constraints", the leisure facilitators can be defined as those factors that facilitate participation in and increase the number of repetition of leisure activities while strengthening the urge for participation and providing the chance to benefit from the advantages of the activities [23]. Korotkov et al. [24], likewise, defined leisure facilitators as the facilities that help access the activities for participation and leisure satisfaction. That is to say, if an individual participates into an activity he/she definitely possesses some facilitating factors and if he/she cannot participate into an activity he/she must be facing some personal, interpersonal or structural constraints $[13,25]$. If we are to formulate the leisure facilitators and constraints, the formula can be stated as 3C1P. "P" denotes participation or nonparticipation and " $3 \mathrm{C}$ " denotes the personal, interpersonal and structural causes. All three causes determine the participation or non-participation behavior [26].

The personal facilitators relating to the personal characteristics, interests, beliefs and attitudes were defined by Raymore [13] deriving from the model developed by Crawford et al. [23]. The personal facilitators are the determining factors in the selection of the activities and they include the personal expectations and choices of the individual. The interpersonal facilitators are those factors helping an individual's participation in an activity as a person or in a group by the effect of the factors such as family support, social environment or peer group, in interaction with one's environment. These facilitators rely on the fact that individuals are interdependent and in interaction in their social environment [27]. Lastly, the structural facilitators are considered as the factors that encourage the individual in activity participation such as the social and physical conditions and the social belief systems. The ethnic background, gender, facilities, socio-economic status and health status can be counted under this category. The climate condition, media, transportation and easy access to the facilities can also be grouped as structural factors. In order to understand the structural factors as a whole, the structure and viewpoint of a society need to be understood [13]. The factors such as the demographic characteristics, the education system and institutions that encourage the individuals into activity participation also constitute a significant role
[28]. The survey of the research conducted in different demographic settings and different cultures demonstrates that the facilitators can be influenced by the demographic factors and their effects on the individuals can vary $[18$, $19,20,21]$.

\section{Material and methods}

Participants.

The research sample consisted of 243 university students (111 female students and 132 male students) who were enrolled in three different faculty of sport sciences. The ages of the participants ranged between 17 and 27, and the age average of the sample was $20.57 \pm 2.16$.

Research Design.

The survey method, which is widely used in descriptive research models, was applied in this study. This method is generally executed on large groups and it targets to reveal the opinions and attitudes of individuals in a group on a case or a phenomenon $[29,30]$. The data collection technique in the study was applying questionnaires, a technique which is also often utilized in studies using the survey method [31].

The data collection tool was the Leisure Facilitator Scale (LFS) developed by Kim et al., [14]. For the usage rights of the scale, the permission of the author was obtained via electronic mail. The original form of the LFS was constituted in three sub-dimensions (personal facilitators, interpersonal facilitators and structural facilitators) and involved 27 items in total. The scale items were scored as (1) 'Unimportant', (2) 'Rather Unimportant, (3) 'Rather Important', (4) 'Important' and (5) 'Very Important'. In adapting the LFS into Turkish the intercultural scale adaptation steps were followed [32]. In this respect, first we checked out whether the target concepts were existent in the present culture or not. Then, we tried to decide whether our evaluations on the results would prove meaningful or not. Upon positive opinion, the next step was to generate the Turkish form of the scale items. While generating the form, translation and back translation methods were used. The generated form was sent to the academic experts in scale development discipline and it was applied on a pilot sample of 35 students to check the clarity and comprehensibility of the scale statements.

The LFS was made fit for the reliability and validity analysis after the abovementioned steps. The application of the data collection tool over the participants required the permission of the students' professors and department and faculty chairs. After the permissions were obtained the questionnaires were filled before the class hours.

\section{Statistical Analysis}

The statistical analyses were executed through SPSS 20 ve AMOS 19 package programs. In order to provide proofs for the factor structure confirmatory factor analysis was made [33]. The correlations between the factors were examined using Pearson Correlation Analysis to provide proof for the validity of the scale. For examining the reliability of the total scale and the sub-dimensions of the tested model internal coherence coefficients were 
calculated. For determining whether there was significant difference between the scores obtained from the scale according to some variables MANOVA was used for the groups independent from the parametric tests. Finally, skewness and curtosis values and Levene test scores were examined in order to determine whether the data met the preconditions of the parametric tests [34].

\section{Results}

In this study, a confirmatory factor analysis was performed in order to validate the three-factor structure that was consisted of 27 items. When the items with low factor loaded value and high error variance (items 6, 7, 8, $10,11,15,16,17,18,19,26)$ were omitted from the scale and the CFA was reapplied, improvements were spotted in the fit indices (Table 1). The item factor load values varied between 0.49 and 0.76 .

Table 2 presents the Cronbach Alpha internal coherence coefficients for the sub-dimensions and the total scale, and the correlation between the factors. The correlations measured between the scale scores varied between 0.40 and 0.84 . The Cronbach Alpha coefficients for the total scale and the sub-dimensions were calculated as $0.86,0.66$ and 0.79 , respectively.

Table 1. Confirmatory Factor Analysis Scores
The mean of the total scores and the standard deviation value for the participants subject to the LFS were 3.72 and 0.61 , respectively. When the LFS scores were analyzed on factorial basis, it was observed that the highest average (3.94) was scored on the 'personal facilitators' subdimension and the lowest (3.42) on the 'interpersonal facilitators. The skewness and kurtosis coefficients, on the other hand, demonstrated that the data met the normalcy assumption for the preconditions of the parametric tests (Table 3).

The MANOVA scores demonstrated that the basic effect of the gender variable on the LFS sub-dimensions was significant $[\lambda=0.964, \mathrm{~F}(2,998)=3.239, \mathrm{p}<0.03]$. In our study, ANOVA was also applied in order to detect which dependent variables contributed significantly to the multi-variable structure. It was concluded that 'personal facilitators' scores $[\mathrm{F}(1,241)=4.416, \mathrm{p}<0.05]$ and 'interpersonal facilitators' sub-dimension scores $[\mathrm{F}(1,241)=4.459, \mathrm{p}<0.05] \quad$ significantly varied in terms of gender main effect. In all sub-dimensions where significant variation was noted the average scores of the male participants were higher than those of the female participants (Table 4)

$\begin{array}{llllllllll}\chi^{2} & \mathbf{d f} & \chi^{2} / \mathbf{d f} & \text { GFI } & \text { CFI } & \text { IFI } & \text { TLI } & \text { RMR } & \text { SRMR } & \text { RMSEA }\end{array}$

$\begin{array}{llllllllll}192.02 & 100 & 1.92 & 0.91 & 0.92 & 0.92 & 0.90 & 0.08 & 0.06 & 0.06\end{array}$

Table 2. The Sub-dimensional Correlation and Internal Coherence Scores of the LFS

\begin{tabular}{|c|c|c|c|c|c|}
\hline LFS (Subscales) & PF & IPF & SF & Total & Alpha \\
\hline Personal Facilitators (PF) & 1 & & & & 0.79 \\
\hline Interpersonal Facilitators (IPF) & $0.40^{* *}$ & 1 & & & 0.66 \\
\hline Structural Facilitators (SF) & $0.55^{* *}$ & $0.54^{* *}$ & 1 & & 0.78 \\
\hline Total & $0.78^{* *}$ & $0.82^{* *}$ & $0.84^{* *}$ & 1 & 0.86 \\
\hline
\end{tabular}

Table 3. The Distribution of the Scale Scores

\begin{tabular}{lccccc}
\hline Sub-dimensions & Mean & SD & Skewness & Curtosis & Min. - Max. \\
\hline Personal Facilitators (PF) & 3.94 & 0.69 & -0.77 & 0.85 & $1.40-5.00$ \\
Interpersonal Facilitators (IPF) & 3.42 & 0.85 & -0.33 & -0.52 & $1.00-5.00$ \\
Structural Facilitators (SF) & 3.80 & 0.71 & -0.53 & 0.41 & $1.00-5.00$ \\
Total & 3.72 & 0.61 & -0.38 & -0.25 & $1.98-5.00$ \\
\hline
\end{tabular}


Table 4. The MANOVA Scores According to the Gender Variable

\begin{tabular}{|c|c|c|c|c|c|c|}
\hline & $\begin{array}{l}\text { Female } \\
(n=111)\end{array}$ & $\begin{array}{l}\text { Male } \\
\text { (n=13 }\end{array}$ & & & & \\
\hline LFS (Subscales) & Mean & SD & Mean & SD & $\mathrm{F}$ & $\mathrm{p}$ \\
\hline Personal Facilitators (PF) & 3.84 & 0.73 & 4.03 & 0.64 & 4.42 & $0.04^{*}$ \\
\hline Interpersonal Facilitators (IPF) & 3.30 & 0.86 & 3.53 & 0.82 & 4.46 & $0.04 *$ \\
\hline Structural Facilitators (SF) & 3.78 & 0.70 & 3.81 & 0.72 & 0.18 & 0.67 \\
\hline
\end{tabular}

\section{Discussion}

According to the results of the CFA for providing evidence for the factorial structure of the LFS, the threefactor and 27-item structure could not be verified. On the other hand, 16-item and three-factor structure proved statistically and theoretically suitable. Based on the fact that $\chi^{2} /$ sd ratio was under 3 , it was observed that there was perfect fit between the data and the model [35]. The GFI value as 0.91 denoted perfect fit whereas the values of CFI as 0.92 , IFI as 0.92 , TLI as 0.90 , RMR as 0.08 , SRMR as 0.06 and RMSEA as 0.06 implied acceptable fit [36]. The result of the analyses made to determine the reliability level of the scale demonstrated that the reliability coefficients obtained from the subdimensions of the scale were generally adequate for the reliability of the test scores [37]. The value obtained for the "interpersonal facilitators" sub-dimension of the scale was 0.66 and this value within the acceptable limits was accordable with the value of 0.61 obtained in the original version of the LFS [14]. Another finding derived for the factor structure of the LFS was positive and medium/high level correlation between the sub-dimensions of the scale.

The second objective of the study was the analysis of the LFS scores of the participants according to the gender variable. In this respect, whereas there was no significant difference at the 'structural facilitators` sub-dimension the scores of the other sub-dimensions differed significantly according to the gender variable. The average scores of the male participants were higher than the scores of the female participants. This result were similar to the studies in the literature. This situation might have arisen from the fact that the male participants of the study group might have benefited more actively from the personal and interpersonal facilitators in the leisure activities they preferred.

\section{Conclusion}

In conclusion, this study suggests that the Turkish adaptation of the Leisure Facilitator Scale can be a valid and reliable measurement tool in determining the leisure facilitating factors of the individuals for the age group (ages 17-27) concerned. The adapted scale can also be a guiding tool for future studies on this issue. On the other hand, since the study sample was composed of only students from faculty of sport sciences it can be considered as a limitation of the study. With its three sub-dimensions and 16 items, for the adapted LFS to be accepted valid and reliable for the entire Turkish culture, further complementary studies with samples from different age groups would be needed.

\section{Conflict of interest}

The authors declare no conflict of interest.

\section{References}

1. Gürbüz B, Henderson K. Leisure activity preferences and constraints to leisure: perspectives from turkey, World Leisure Journal, 2014, 56(4), 300- 316. https://doi.org/10.1080/16078055.2014.958195

2. Iso-Ahola SE. Toward a dialectical social psychology of leisure and recreation. 1980.

3. Kim J-H, Brown SL, Yang H. Types of leisure, leisure motivation, and well-being in university students. World Leisure Journal, 2019;61:43-57. https://doi.org/10.1080/16078055.2018.1545691

4. Kraus RG. Leisure in a changing America: Multicultural perspectives. Macmillan College. Publishing Company; 1994.
5. Chick G, Hsu Y-C, Yeh C-K, Hsieh C-M. Leisure Constraints, Leisure Satisfaction, Life Satisfaction, and Self-Rated Health in Six Cities in Taiwan. Leisure Sciences, 2015;37:232-51. https://doi.org/10.1080/01490400.2014.967897

6. Murphy H. Exploring leisure and psychological health and wellbeing: some problematic issues in the case of Northern Ireland. Leisure Studies, 2003; 22(1): 37-50. https://doi.org/10.1080/02614360306570

7. Crawford DW, Godbey G. Reconceptualizing barriers to family leisure. Leisure sciences, 1987; 9(2): 119-127. https://doi.org/10.1080/01490408709512151

8. Chick G, Dong E. Cultural constraints on leisure. In: E. L. Jackson (Editor), Constraints to leisure. State College, PA: Venture Publishing; 2005. P. 169-183. 
9. Jackson EL. Leisure constraints research: Overview of a developing theme in leisure studies. In E. L. Jackson (editor), Constraints to leisure. State College, PA: Venture Publishing; 2005.

10.Mowen AJ, Payne LL, Scott D. Change and stability in park visitation constraints revisited. Leisure Sciences, 2005; 27: 191-204. https://doi.org/10.1080/01490400590912088

11. Wood L, Danylchuk K. Constraints and negotiation processes in a women's recreational sport group. Journal of Leisure Research, 2012; 44: 463-485. https://doi.org/10.1080/00222216.2012.11950274

12.Evans K, Gagnon RJ. A structural model exploring gender differences in perceived constraints to competition climbing. Annals of Leisure Research, 2018:1-19. https://doi.org/10.1080/11745398.2018.1534598

13.Raymore L. Facilitators to leisure. Journal of Leisure research, 2002; 34(1): 37-51. https://doi.org/10.1080/00222216.2002.11949959

14.Kim B, Heo J, Chun S, Lee Y. Construction and initial validation of the leisure facilitator scale. Leisure/Loisir, 2011; 35(4): 391-405. https://doi.org/10.1080/14927713.2011.648402

15.Hubbard J, Mannell RC. Testing competing models of the leisure constraint negotiation process in a corporate employee recreation setting. Leisure sciences, 2001;23(3): 145-163. https://doi.org/10.1080/014904001316896846

16.Kennelly M, Moyle B, Lamont M. Constraint negotiation in serious leisure: A study of amateur triathletes. Journal of Leisure Research, 2013; 45: 466-484. https://doi.org/10.18666/jlr-2013-v45-i4-3895

17.MacCosham B. Negotiating leisure constraints: the case of an amateur musician with epilepsy, Leisure Studies, 2017; 36(6): 825-837. https://doi.org/10.1080/02614367.2017.1285955

18. Alvarado M, Murphy MM, Guell C. Barriers and facilitators to physical activity amongst overweight and obese women in an Afro-Caribbean population: A qualitative study. International Journal of Behavioral Nutrition and Physical Activity 2015;12. https://doi.org/10.1186/s12966-015-0258-5.

19.Kang HY, Kim HH, Choi HW, Lee WI, Lee CW. Relationship between Leisure Facilitators and Serious Leisure among Female Korean College Soccer Participants. Asian Social Science, 2017, 13(4), 117-124. https://doi.org/10.5539/ass.v13n4p117

20.Emir E, Küçük Kılıç S, Gürbüz B, Öncü E. Leisurely participation of Turkish women's: Constraints and facilitators. 14th International Sport Sciences Congress 01st-04th November, Antalya: Turkey; 2016.

21.Koçak F. Leisure Constraints And Facilitators: Perspectives From Turkey. European Journal of Physical Education and Sport Science, 2017; 3 (10): 32-46.

22.Sarol H. Examination of the constraints and facilitators to physical activity participation of individuals. Journal of Human Sciences, 2017; 14(4): 4354-4364. https://doi.org/10.14687/jhs.v14i4.5121

23.Crawford DW, Jackson EL, Godbey G. A hierarchical model of leisure constraints. Leisure sciences, 1991; 13(4): 309-320. https://doi.org/10.1080/01490409109513147

24.Korotkov D, McLean H, Hamilton L. Predicting leisure satisfaction: A comparative analysis of the agency and communion model with the five-factor model of personality. The American Association of Behavioral and Social Sciences Journal, 2011;15: 1-20.

25.Stensland S, Aas Q, Mehmetoğlu M. Understanding Constraints and Facilitators to Salmon Angling Participation: Insights from Structural Equation Modeling, Human Dimensions of Wildlife, 2017; 22(1): 1-17. https://doi.org/10.1080/10871209.2016.1199073

26.Allen LR. Benefits of leisure attributes to community satisfaction.JournalofLeisureResearch, 1990;22(2): 183-196. https://doi.org/10.1080/00222216.1990.11969824

27.Henderson KA, Estes CA. New terms, broader approaches: Recreation and social ecology of physical activity. Parks and Recreation, 2002; 35: 28-34.

28.Bertrais S, Preziosi P, Mennen L, Galan P, Hercberg S, Oppert JM. Sociodemographic and geographic correlates of meeting current recommendations for physical activity in middle-aged French adults: the Supplementation en Vitamines et Mineraux Antioxydants (SUVIMAX) Study. American Journal of Public Health, 2004; 94(9): 1560-1566. https://doi.org/10.2105/AJPH.94.9.1560

29.Jones I, Gratton C. Research methods for sports studies. London: Routledge; 2004.

30.Thomas JR, Nelson JK. Research methods in physical activity (3rd ed.). Champaing, IL: Human Kinetics; 1996.

31.Frankfort-Nachmias C, Nachmias D. Index construction and scaling methods. Frankfort-Nachmias C, Nachmias D. Research methods in the social sciences, London: St Martin's Press; 1996.

32.Hambleton RK, Patsula L. Increasing the validity of adapted tests: Myths to be avoided and guidelines for improving test adaptation practices. Journal of Applied Testing Technology, 1999; 1(1): 1-30.

33.McIntire SA, Miller LA. Foundations of psychological testing. Fairfield, PA: McGraw-Hill Companies; 2000.

34.Kline RB. Principles and practice of structural equation modeling. New York: Guilford Press; 2005.

35.Byrne BM. Structural equation modeling with AMOS: Basic concepts, applications, and programming. Routledge; 2010.

36. Hu L, Bentler PM. Cutoff criteria for fit indexes in covariance structure analysis: Conventional criteria versus new alternatives. Structural Equation Modeling: A Multidisciplinary Journal, 1999; 6: 1-55. https://doi.org/10.1080/10705519909540118

37.Büyüköztürk S. Sosyal bilimler için veri analizi el kitabı (9.Basım) [Data analysis handbook for social sciences (9th ed.)]. Ankara: Pegem Akademi; 2008. (in Turkish)

38.Koçak F, Gürbüz B, Doğaner S, Özbek, O. Relationship Among Leisure Facilitators, Leisure Constraints, and Leisure Involvement: Structural Equation Modelling Study. 16th International Sports Sciences Congress, 2018, 31 October03 November. Antalya: Turkey; 2018. P. 64-65. 


\section{Information about the authors:}

Gürbüz B.: (Corresponding author); http://orcid.org/0000-0003-2424-2111; bulentgurbuz@gmail.com; Faculty of Sport Sciences, Department of Sports Management, Ankara University, ; Ankara University Golbasi Campus, Ankara, Turkey.

Öncü E.; http://orcid.org/0000-0002-7932-5558; ermanoncu@gmail.com; Faculty of Sport Sciences, Department of Physical Education and Sport Teaching, Trabzon University, ; Trabzon University Sogutlu Mah. Akçaabat, Trabzon, Turkey.

Emir E.; http://orcid.org/0000-0003-0547-5112; emiresraa@gmail.com; Yaşar Doğu Faculty of Sport Sciences, Department of Physical Education and Sport Teaching, Ondokuz Mayıs University, ; Ondokuz Mayıs University, Korfez Mah, Atakum, Samsun, Turkey.

\section{Cite this article as:}

Gürbüz B, Öncü E, Emir E. The Turkish adaptation of leisure facilitator scale: a validity and reliability study. Physical education of students, 2019;23(2):64-69.

https://doi.org/10.15561/20755279.2019.0202

The electronic version of this article is the complete one and can be found online at: https://sportedu.org.ua/index.php/PES/issue/archive

This is an Open Access article distributed under the terms of the Creative Commons Attribution License, which permits unrestricted use, distribution, and reproduction in any medium, provided the original work is properly cited http://creativecommons.org/licenses/by/4.0/deed.en

Received: 03.03.2019

Accepted: 24.04.2019; Published: 28.04.2019 